\title{
New steroidal compounds from an actinomycete strain, Lechevalieria aerocolonigenes K10-0216
}

\author{
Takuji Nakashima $^{1}$, Yoshiyuki Kamiya ${ }^{2}$, Kenzaburo Yamaji ${ }^{3}$, Masato Iwatsuki ${ }^{2,3}$, Noriko Sato ${ }^{4}$, \\ Yōko Takahashi ${ }^{2}$ and Satoshi Ōmura ${ }^{3}$
}

The Journal of Antibiotics (2015) 68, 348-350; doi:10.1038/ja.2014.152; published online 10 December 2014

\begin{abstract}
Secondary metabolites of actinomycetes represent important and major sources of new natural products. Since streptomycin was discovered by Selman Waksman, a large number of biological compounds, in many research areas, such as medicine, organic chemistry and cell biology, have been isolated from cultured broths of actinomycetes. ${ }^{1-4}$ More than 22000 bioactive compounds have been discovered from secondary metabolites of microorganisms, such as actinomycetes, fungi and bacteria. Of those, $\sim 40 \%$ arose from secondary metabolites of actinomycetes. ${ }^{2-4}$ The main strategy in discovering new compounds involves biological screening, in which guided assays are used for the isolation of bioactive compounds. However, the discovery of new compounds from microbial cultured broths suffers from duplication of isolated compounds. As the rate of discovery of completely novel natural products has slowed, new approaches are continually being sought.
\end{abstract}

The physicochemical (PC) properties of compounds, such as UV-visible absorption spectrum, MW and molecular formula, can be detected by LC/UV and LC/MS analyses of microbial cultured broths. PC screening of cultured broths uses advanced analytical technology to swiftly avoid chemical duplicates. Our ongoing PC screening program has recently identified trehangelins ${ }^{5}$ and mangromicins ${ }^{6,7}$ as new compounds, isolated from broths of rare actinomycetes, Polymorphospora rubra K07-0510 and Lechevalieria aerocolonigenes K10-0216, respectively. Moreover, PC screening identified two new compounds, K10-0216 KA (1) and $\mathrm{KB}$ (2), from same broth of $L$. aerocolonigenes K10-0216 that produced mangromicins. This paper describes the fermentation, isolation, structure determination and brief biological activity of 1 and 2.

A loop of spores of strain K10-0216 was inoculated into $100 \mathrm{ml}$ of seed medium consisting of $2.4 \%$ starch, $0.1 \%$ glucose, $0.3 \%$ peptone, $0.3 \%$ meat extract, $0.5 \%$ yeast extract and $0.4 \% \mathrm{CaCO}_{3}$ (adjusted to $\mathrm{pH} 7.0$ before sterilization) in a $500-\mathrm{ml}$ Erlenmeyer flask. The flask was incubated on a rotary shaker (210 r.p.m.) at $27^{\circ} \mathrm{C}$ for 3 days.
A 1-ml portion of the seed culture was transferred to 500-ml Erlenmeyer flasks (total 161), each containing $100 \mathrm{ml}$ of production medium consisting of $2.0 \%$ soluble starch, $0.5 \%$ glycerol, $1.0 \%$ defatted wheat germ, $0.3 \%$ Ehlrich meat extract from Katsuwonus pelamis (Kyokuto Pharmaceutical Inc., Tokyo, Japan) and 0.3\% dry yeast, $0.3 \% \mathrm{CaCO}_{3}$ (adjusted to $\mathrm{pH} 7.0$ before sterilization) and fermentation was carried out on a rotary shaker (210 r.p.m.) at $27^{\circ} \mathrm{C}$ for 7 days. The whole culture broth (161) was centrifuged to separate mycelium and supernatant. The supernatant was passed through a column of Diaion HP-20 $(75 \times 200 \mathrm{~mm}$, Nihon Rensui Co, Tokyo, Japan) previously equilibrated with water. After washing with water, the fraction containing 1 was eluted with $40 \% \mathrm{MeOH}$. The fraction containing 2 was then eluted with $100 \% \mathrm{MeOH}$. The $40 \% \mathrm{MeOH}$ fraction and $100 \% \mathrm{MeOH}$ fraction were concentrated in vacuo to dryness to yield 150 and $611 \mathrm{mg}$ of dry extract, respectively. The $40 \%$ fraction $(150 \mathrm{mg}$ ) was applied on an ODS column $(20 \times 150 \mathrm{~mm}$, Senshu Scientific Co, Tokyo, Japan) previously equilibrated with water. After washing with water and $40 \% \mathrm{MeOH}$, the fraction containing 1 was eluted with $60 \% \mathrm{MeOH}$. The $60 \% \mathrm{MeOH}$ fraction was concentrated to yield $46.2 \mathrm{mg}$. The fraction was dissolved in a small amount of $\mathrm{MeOH}$ and purified by HPLC on an Inertsil ODS-4 column (10 i.d. $\times 250 \mathrm{~mm}$, GL sciences Inc., Tokyo, Japan) with $18 \%$ acetonitrile at $6 \mathrm{ml} \mathrm{min}^{-1}$ detected at UV $254 \mathrm{~nm}$. The yield of 1 was $3.0 \mathrm{mg}$. (Supplementary Scheme S1).

The $100 \%$ fraction $(611 \mathrm{mg})$ was applied on an ODS column $(20 \times 150 \mathrm{~mm}$, Senshu Scientific Co. $)$ previously equilibrated with water. After washing with $80 \% \mathrm{MeOH}$, the fraction containing 2 was eluted with $100 \% \mathrm{MeOH}$. The $100 \% \mathrm{MeOH}$ fraction was concentrated to yield $44.2 \mathrm{mg}$. The fraction was dissolved in a small amount of $\mathrm{MeOH}$ and purified with HPLC on an Inertsil ODS-4 column (10 i.d. $\times 250 \mathrm{~mm}$, GL sciences Inc.) with $20 \%$ acetonitrile. The yield of 2 was $4.3 \mathrm{mg}$ (Supplementary Scheme S1).

${ }^{1}$ Research Organization for Infection Control Sciences, Kitasato University, Tokyo, Japan; ${ }^{2}$ Graduate School of Infection Control Sciences, Kitasato University, Tokyo, Japan, ${ }^{3}$ Kitasato Institute for Life Sciences, Kitasato University, Tokyo, Japan and ${ }^{4}$ Graduate School of Pharmaceutical Sciences, Kitasato University, Tokyo, Japan Correspondence: Dr T Nakashima, Research Organization for Infection Control Sciences, Kitasato University, Minato-ku, Tokyo 108-8641, Japan.

E-mail: takuji@lisci.kitasato-u.ac.jp

or Dr Y Takahashi, Kitasato Institute for Life Sciences, Kitasato University, 5-9-1 Shirokane, Minato-ku, Tokyo 108-8641, Japan.

E-mail: ytakaha@lisci.kitasato-u.ac.jp

Received 3 July 2014; revised 10 October 2014; accepted 14 October 2014; published online 10 December 2014 
Compounds 1 and 2 are both readily soluble in $\mathrm{MeOH}$ and showed absorption maxima at 237 and $240 \mathrm{~nm}$ in UV spectra, respectively. The IR absorption at $\sim 3400$ and $1680 \mathrm{~cm}^{-1}$ in both compounds suggested the presence of hydroxyl and carbonyl groups. The physicochemical properties are similar in both compounds (Supplementary Table S1).

Compound 1 was obtained as a pale-yellow powder determined to have the molecular formula of $\mathrm{C}_{19} \mathrm{H}_{26} \mathrm{O}_{4}$ by HRESIMS $[\mathrm{M}+\mathrm{H}]^{+} \mathrm{m} / \mathrm{z}$ 319.1903 (calcd. for $\mathrm{C}_{19} \mathrm{H}_{27} \mathrm{O}_{4}, 319.1909$ ), requiring seven unsaturation degrees. The $1 \mathrm{D}$ and $2 \mathrm{D}$ NMR spectra of 1 were measured in $\mathrm{CD}_{3} \mathrm{OD}$. The ${ }^{1} \mathrm{H}$ NMR data of $\mathbf{1}$ indicated the presence of three oxygenated $s p^{3}$ methines, one olefinic proton, six methylenes and two tertiary methyls. The ${ }^{13} \mathrm{C}$ NMR spectrum showed the resonances of 19 carbons, which were classified into four olefinic carbons at $\delta_{\mathrm{c}}$ $121.4,130.9,132.8$ and 169.4 , one carbonyl carbon at $\delta_{\mathrm{c}} 199.9$, three oxygenated $s p^{3}$ methine carbons at $\delta_{\mathrm{c}} 74.6,78.4$ and 81.3 , one $s p^{3}$ methine carbon, two $s p^{3}$ quaternary carbons, six $s p^{3}$ methylene carbons and two methyl carbons with HSQC spectra (Supplementary Table S2). One carbonyl group and two olefin groups accounted for three of the seven unsaturation degrees, indicating the existence of four rings in 1 . The ${ }^{1} \mathrm{H}^{-1} \mathrm{H}$ COSY indicated the presence of four partial structures: a, C-1/C-2; b, C-4/C-7; c, C-11/C-12; and d, C-14/C-17 (Figure 1a).

The HMBC correlations from $\mathrm{H}-1$ to $\mathrm{C}-2, \mathrm{C}-3, \mathrm{C}-5, \mathrm{C}-10$ and C-10-Me; from H-2 to C-3; from H-4 to C-2, C-6 and C-10 revealed the presence of $\alpha, \beta$-unsaturated cyclohexanone moiety. The HMBC correlations from $\mathrm{H}_{2}-6$ to C-4, C-5, C-7, C-8 and C-10; from $\mathrm{H}_{2}-7$ to C-5, C-6, C-8 and C-9; from $\mathrm{H}_{3}-10-\mathrm{Me}$ to $\mathrm{C}-1$,
C-5, C-9 and C-10 indicated the presence of a decaline moiety, including partial structures $\mathrm{a}$ and $\mathrm{b}$, in 1 . Finally, the planar structure of 1 was elucidated as shown in Figure 1a by the HMBC correlations from $\mathrm{H}_{2}-11$ to $\mathrm{C}-10$ and C-13; from $\mathrm{H}_{2}-12$ to C-9, C-11, C-13, C-14 and C-13-Me, including partial structures c, from $\mathrm{H}-14$ to C-8; from $\mathrm{H}_{2}-15$ to C-8, C-13, C-14, C-16 and C-17; from $\mathrm{H}_{2}-16$ to $\mathrm{C}-13, \mathrm{C}-15$ and $\mathrm{C}-17$; from $\mathrm{H}-17$ to $\mathrm{C}-12, \mathrm{C}-16$ and $\mathrm{C}-13-\mathrm{Me}$, including partial structures $\mathrm{d}$, from $\mathrm{H}_{3}-13-\mathrm{Me}$ to $\mathrm{C}-12$, C-13, C-14 and C-17.

The relative configuration of $\mathbf{1}$ was estimated using ROESY experimentation (Figure 1b). The ROESY correlations were observed between $\mathrm{H}-1 / \mathrm{H}-2, \mathrm{H}-1 / \mathrm{H}-11 \mathrm{a}, \mathrm{H}-1 / \mathrm{H}_{3}-10-\mathrm{Me}, \mathrm{H}-2 / \mathrm{H}_{3}-10-\mathrm{Me}, \mathrm{H}-4 /$ H6b, H-6a/H $3-10-M e, H-7 a / H-15 a, H-11 a / H_{3}-10-M e, H-11 a / H_{3}-13-$ Me, H-12b/H-14, H-12b/H-17, H-14/H-17 and $\mathrm{H}-15 \mathrm{a} / \mathrm{H}_{3}-13-\mathrm{Me}$. These results indicate that $\mathrm{H}-1, \mathrm{H}-2, \mathrm{H}_{3}-10-\mathrm{Me}$ and $\mathrm{H}_{3}-13-\mathrm{Me}$ are located on the identical face. Therefore, the relative configuration of $\mathbf{1}$ was proposed as $1 R^{\star}, 2 R^{\star}, 10 S^{\star}, 13 S^{\star}, 14 S^{\star}$ and $17 S^{\star}$, and a $14 \alpha \mathrm{H}$ steroid skeletal compound (Figure 2).

Compound 2 was obtained as a pale-yellow powder determined to have the molecular formula of $\mathrm{C}_{19} \mathrm{H}_{24} \mathrm{O}_{4}$ by HRESIMS $[\mathrm{M}+\mathrm{H}]^{+} \mathrm{m} / \mathrm{z}$ 317.1708 (calcd. for $\mathrm{C}_{19} \mathrm{H}_{25} \mathrm{O}_{4}, 317.1735$ ). The $1 \mathrm{D}$ and $2 \mathrm{D}$ NMR spectra of 2 were measured in $\mathrm{CD}_{3} \mathrm{OD}$. From a comparison of chemical shifts in the ${ }^{1} \mathrm{H}$ and ${ }^{13} \mathrm{C}$ NMR of 2 with those of 1 , the signals of a carbonyl group $\left(17-\mathrm{C} ; \delta_{\mathrm{C}} 222.7\right)$ were observed in 2 instead of those of the hydroxy group $\left(17-\mathrm{CH} ; \delta_{\mathrm{H}} 3.68 / \delta_{\mathrm{C}} 81.3\right)$ in 1 (Supplementary Table S2). Analysis of HMBC data confirmed the presence of a cyclopentanone, based on correlations from $\mathrm{H}_{2}-15$ to C-17; from $\mathrm{H}_{2}-16$ to $\mathrm{C}-14$ and $\mathrm{C}-17$; and from $\mathrm{H}_{3}-13-\mathrm{Me}$ to C-14.

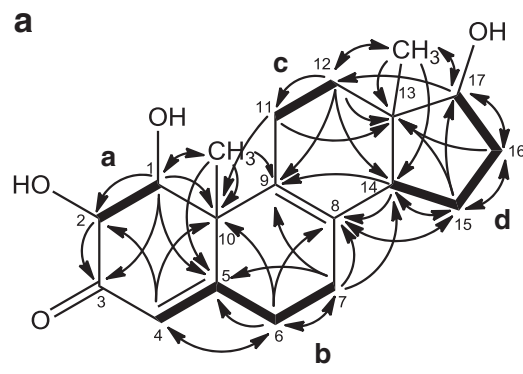

1

b

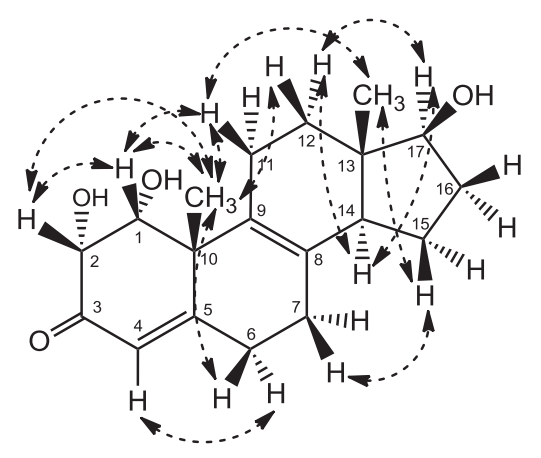

1
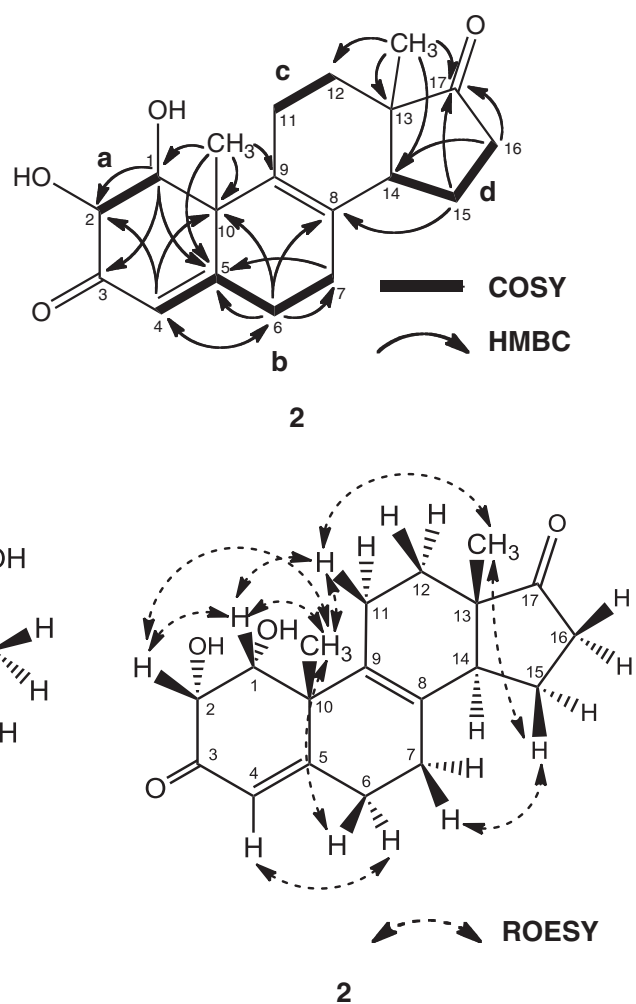

Figure 1 (a) ${ }^{1} \mathrm{H}-{ }^{1} \mathrm{H}$ COSY (bold) and selected HMBC (arrow) correlations of K10-0216 KA (1) and KB (2). (b) Key ROESY correlations (arrow dot) of K10-0216 KA (1) and KB (2). 
<smiles>C[C@@]12C(=CC(=O)[C@H](O)[C@H]1O)CCC1=C2CC[C@]2(C)[C@@H](O)CC[C@]12C</smiles>

1

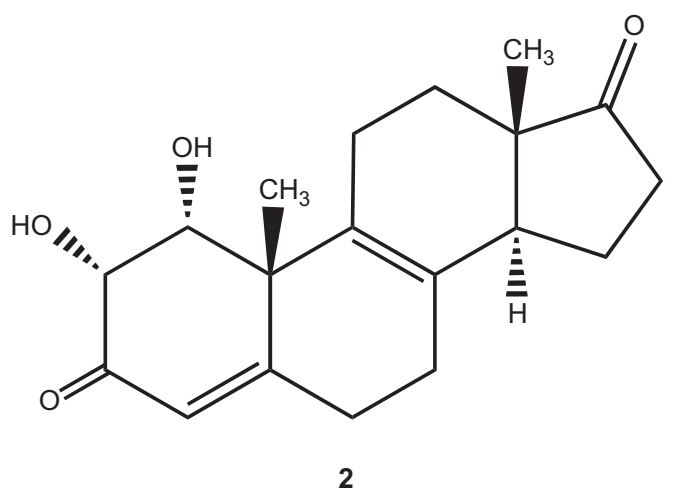

Figure 2 Relative configurations of K10-0216 KA (1) and KB (2).

Therefore, the planar structure of $\mathbf{2}$ was elucidated as a 17-dehydroxyl17-oxo analog of 1 (Figure 1). The ROESY correlations of 2 were almost similar to those of $\mathbf{1}$ (Figure 1). These results suggested that $\mathbf{2}$ had the relative configuration of $1 R^{\star}, 2 R^{\star}, 10 S^{*}, 13 S^{\star}$ and $14 S^{\star}$ (Figure 2).

Compound 2 showed slightly stronger inhibitory effect on the lipid accumulation in 3T3-L1 adipocytes than testosterone. However, no effect of 1 on the lipid accumulation was observed, even at $100 \mu \mathrm{M}$ (Supplementary Figure S1). Moreover, lipid accumulation was inhibited by treatment with 2 in a concentrationdependent manner (Supplementary Figure S1). The structural difference between $\mathbf{1}$ and $\mathbf{2}$ was a hydroxyl group and carbonyl group, respectively, bound at the $\mathrm{C}-17$ position. In comparision between 1 and 2 , it was suggested that the carbonyl group at the $\mathrm{C}-17$ position is important in the inhibition of lipid accumulation in 3T3-L1 adipocytes.

\section{ACKNOWLEDGEMENTS}

This study was supported by funds from the Institute for Fermentation (IFO), Osaka, Japan. We are grateful to Dr Kenichiro Nagai, School of Pharmacy, Kitasato University, for measurements of MS spectra.

1 Newman, D. J. \& Cragg, G. M. Natural products as sources of new drugs over the 30 years from 1981 to 2010. J. Nat. Prod. 75, 311-335 (2012).

2 Bérdy, J. Bioactive microbial metabolites. J. Antibiot. 58, 1-26 (2005).

3 Bérdy, J. Thoughts and facts about antibiotics: where we are now and where we are heading. J. Antibiot. 65, 385-395 (2012).

4 Bérdy, J. Erratum: Thoughts and facts about antibiotics: where we are now and where we are heading. J. Antibiot. 65, 441 (2012).

5 Nakashima, T. et al. Trehangelins A, B and C, novel photo-oxidative hemolysis inhibitors produced by an endophytic actinomycete, Polymorphospora rubra K07-0510. J. Antibiot. 66, 311-317 (2013).

6 Nakashima, T. et al. Mangromicins A and B: structure and anti-trypanosomal activity of two new cyclopentadecane compounds from Lechevalieria aerocolonigenes K10-0216. J. Antibiot. 67, 253-260 (2014).

7 Nakashima, T., Kamiya, Y., Iwatsuki, M., Takahashi, Y. \& Omura, S. Mangromicins, six new anti-oxidative agents isolated from a culture broth of the actinomycete, Lechevalieria aerocolonigenes K10-0216. J. Antibiot. 67, 533-539 (2014)

Supplementary Information accompanies the paper on The Journal of Antibiotics website (http://www.nature.com/ja) 